\title{
Relationship between Pain and Neck Mobility in Patients with Grade II Whiplash Injury
}

\author{
MOHAMED N. EL-BAHRAWY, Ph.D.*; SHERIF G. AL-MEKAWI, M.D.**; WALAA M. RAGAB, Ph.D.* and \\ MAHMOUD M. NABIL, M.Sc.*** \\ The Department of Physical Therapy for Neuromuscular Disorders \& its Surgery, Faculty of Physical Therapy* and \\ The Department of Neurosurgery, Faculty of Medicine**, Cairo University and The Department of Physical Therapy, \\ Beni-Suef University Hospital***, Egypt
}

\begin{abstract}
Background: Patients with grade II whiplash injuries have physical signs of decreasing range of neck movement and palpable tenderness. Many patients with whiplash injury report diffuse symptoms of sensory disturbances and generalised muscle weakness. Whiplash injury has profound effects on both peripheral and central pain-processing mechanisms. Approximately $50 \%$ of subjects who sustain a whiplash injury will not recover but will continue to report ongoing pain and disability one year after the injury.
\end{abstract}

Aim of Study: This study aimed to evaluate the correlation between pain and neck mobility in Egyptian patients with grade II whiplash injury.

Subjects and Methods: Fifteen Egyptian patients with grade II whiplash injury from both genders were selected for this study. All the patients were assessed for pain by visual analogue scale and cervical range of motion by Cervical Range of Motion goniometer (CROM).

Results: There is strong negative significant correlation between level of pain by Visual Analogue Scale (VAS) and neck bending to right and left only.

Conclusion: There is negative correlation between level of pain and side bending to right and left in Egyptian patients with grade II whiplash injury.

Key Words: Whiplash injury - Pain - Visual Analogue Scale (VAS) - Cervical Range of Motion (CROM) goniometer.

\section{Introduction}

WHIPLASH is a traumatic injury to the structures of the cervical spine. It involves muscles and ligaments and is caused by extremes in the range of motion $[1,2]$. The main frequent symptoms associated with the whiplash injury are neck pain $[1,2]$ and limited range of motion [3] .

Correspondence to: Dr. Mahmoud M. Nabil, E-Mail: mnabil 89@yahoo.com
Whiplash injury might affect various anatomical sites including the cervical facet joints and facet capsular ligaments. Also, it might affect vertebral arteries, dorsal root ganglia, craniovertebral junction, and cervical muscles [4-6]. The intervertebral discs and zygapophyseal joints are extensively innervated [7]. So they could serve as primary pain generators in whiplash injury [8] .

Muscle spasms have the capacity to reduce Range of Motion (ROM) and to alter the Instantaneous Axis of Rotation (IAR) [9]. Changes in muscle function occur in the acute state and may persist despite the patient reporting recovery $[10,11]$ Sensorimotor changes in individuals following whiplash injury include loss of movement [12] and altered muscle recruitment patterns [13]. Patients with persistent moderate/severe levels of pain and disability (measured with the Nek Disability Index) continue to display active movement loss several years postinjury [14]

\section{Subjects and Methods}

This study was conducted since May 2016 till September 2017 at the balance laboratory in the Faculty of Physical Therapy, Cairo University. Fifteen Egyptian patients from both genders with grade II whiplash injury according to Québec Task Force classification were selected for this study. All the selected patients were referred from a specialist of Neurosurgery to the outpatient clinic of Faculty of Physical Therapy at Cairo University.

Ethical consideration; the purpose and nature of the study were explained to all subjects. All subjects signed a consent form prior to participation in the study. All patients were required to meet a strict set of inclusion criteria; all the patients were 
in the chronic stage (more than three months after injury), age ranged from 25 to 35 years old, all the patients were medically stable and understanding the orders.

Patients with the following criteria were excluded; history of cervical surgery, history of similar symptoms previous to the accident, severe trauma or skeletal injury (fracture or dislocation), trauma of spinal cord, lumbar radiculopathy or myolopathy, vertigo problems or inner ear disorders and under the influence of alcohol or drugs.

All the included subjects were assessed for neck mobility by Cervical Range of Motion (CROM) goniometer and for pain level by Visual Analogue Scale (VAS) at the outpatient clinic of Faculty of Physical Therapy at Cairo University.

- Visual Analogue Scale (VAS): The visual analogue scale is an instrument with good validity and excellent reliability [15]. It is administered as a paper and pencil measure. The following cut points on the pain VAS have been recommended; no pain $(0-4 \mathrm{~mm})$, mild pain $(5-44 \mathrm{~mm})$, moderate pain $(45-74 \mathrm{~mm})$, and severe pain $(75-100 \mathrm{~mm})$ $[16,17]$

The patients were asked to place a line perpendicular to the VAS line at the point that represents their pain intensity. Using a ruler, the score was determined by measuring the distance $(\mathrm{mm})$ on the $10-\mathrm{cm}$ line between the "no pain" anchor and the patient's mark, providing a range of scores from $0-100$.

- Cervical Range of Motion (CROM) goniometer: The cervical range of motion goniometer measures the cervical range of motion for flexion, extension, lateral flexion, and rotation using

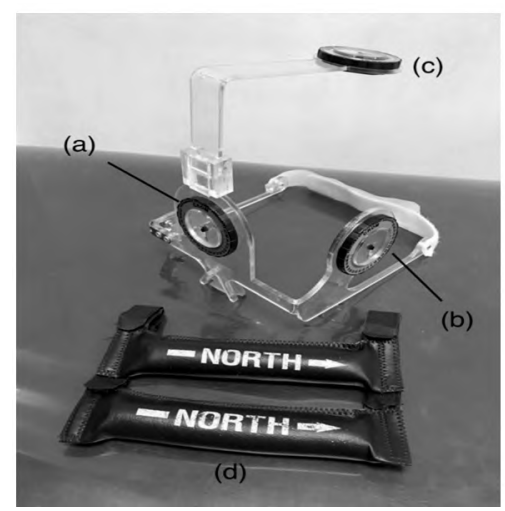

Fig. (1): Cervical Range of Motion (CROM) Goniometer: $(\mathrm{a}, \mathrm{b})$ Inclinometers with a gravity-dependent needles, (c) Inclinometer with a magnetic needle, (d) Magnetic neck brace. Research Laboratory, Faculty of Physical Therapy, Cairo University. separate inclinometers. These inclinometers are attached to a frame similar to that for eyeglasses. The first inclinometer is in the sagittal plane for flexion-extension. The second one is in the frontal plane for lateral flexion, and the third one in the horizontal plane for rotation. Two of these inclinometers have a gravity-dependent needle (in the sagittal and frontal planes), and the other has a magnetic needle (in the horizontal plane). A magnetic neck brace is worn by the patient Fig. (1). This goniometer offers two advantages of easing of use and relative affordability [18,19]

All the patients sat in the comfortable chair with the feet supported on the ground. The strap of the CROM goniometer was fixed around the head of the patients during all the measurements of cervical spine.

For measuring flexion and extension (ROM) of the cervical spine the instrument of the CROM was fixed at the side of patient's head. But it was fixed at the forehead during measuring lateral side bending (ROM) of the cervical spine. Finally it was fixed on the top of the patient's head during measuring rotation (ROM) of the cervical spine Fig. (2).

The inclinometer's needle settled at zero at the start of measurements of all cervical range of motion. The patients were instructed to flex and extend his/her head. Then, they were asked to bend the head laterally until ear meet the shoulder as much as they could for measuring lateral side bending (ROM) of the cervical spine. Also, the patients were instructed to rotate the head to right and left from neutral position as much as they could for measuring rotation (ROM) of the cervical spine. At the end of each cervical motion the reading of measurement was taken.

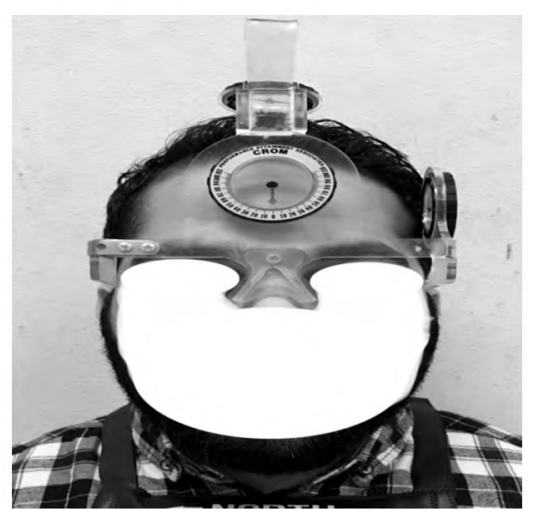

Fig. (2): Patient wears the Cervical Range of Motion (CROM) goniometer as a starting position for assessment. 


\section{Statistical analysis:}

All statistical calculations were done using computer programs Microsoft Excel (Microsoft Corporation, NY, USA) \& SPSS (Statistical package for the social science) statistical programs (SPSS Inc., Chicago, IL, USA). Data were statistically described in terms of mean \pm Standard Deviation ( $\pm \mathrm{SD}$ ), and range, or frequencies (number of cases) and percentages when appropriate. The obtained values from VAS and CROM goniometer were statistically analyzed using Correlation coefficient (Spearman correlation) to correlate between pain and neck mobility.

\section{Results}

The mean age of the subjects was $29.7 \pm 2.7$ years. The mean BMI of the patients was $25.6 \pm 2.2$ $\mathrm{kg} / \mathrm{m} 2$ respectively.

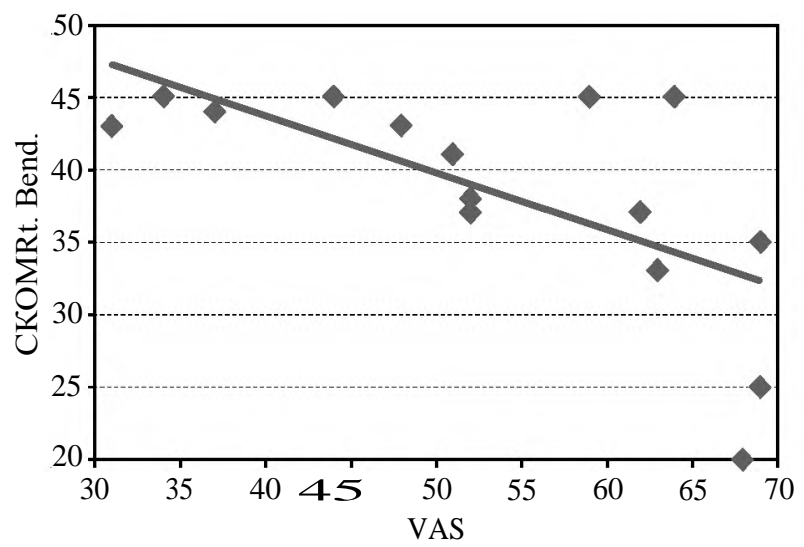

Fig. (3): Correlation between VAS and CROM Rt. Bend.

\section{Discussion}

This study showed a strong negative significant correlation between VAS and bending to right and left in patients who had grade II whiplash injury. This correlation indicates that as VAS increases, the cervical bending movement to right and left decreases, and vice-versa.

This result might be attributed to neck muscle dysfunction which is an early correlate of subclinical neck pain [20]. A common cause of neck pain is mechanical dysfunction, which causes abnormal joint movement, as abnormal cervical joint mobility inside the joint capsule can limit neck movement $[21,22]$. Additionally, disturbances of soft tissue around the head and neck structure consequently limits the Range of Motion (ROM) of the head leading to neck pain [23]

The overactivity of cervical lateral flexors and the dysfunction of deep neck flexors may share in
From the data represented in (Table 1), there is strong negative significant correlation between VAS and bending to right and left $(r=0.7 \& p$ $<0.011)$ and $(r=0.6 \& p<0.025)$ respectively. This correlation indicates that as VAS increases the cervical bending movement to right and left decreases, and vice-versa Figs. $(3,4)$.

Table (1): Correlation between pain measurement by VAS and range of motion measurement by CROM in Egyptian patients with grade II whiplash injury.

\begin{tabular}{lcc}
\hline & \multicolumn{2}{c}{ VAS } \\
\cline { 2 - 3 } & $r$ & $p$-value \\
\hline CROM flexion & 0.1 & 0.725 \\
CROM extension & -0.3 & 0.170 \\
CROM Rt. Bend. & -0.7 & $0.011^{*}$ \\
CROM Lt. bend. & -0.6 & $0.025^{*}$ \\
CROM Rt. Rot. & -0.5 & 0.062 \\
CROM Lt. Rot. & -0.4 & 0.085 \\
\hline
\end{tabular}

$r$ : Correlation coefficient (Spearman correlation)

$*: p$-value (probability value) <0.05 (Significant).

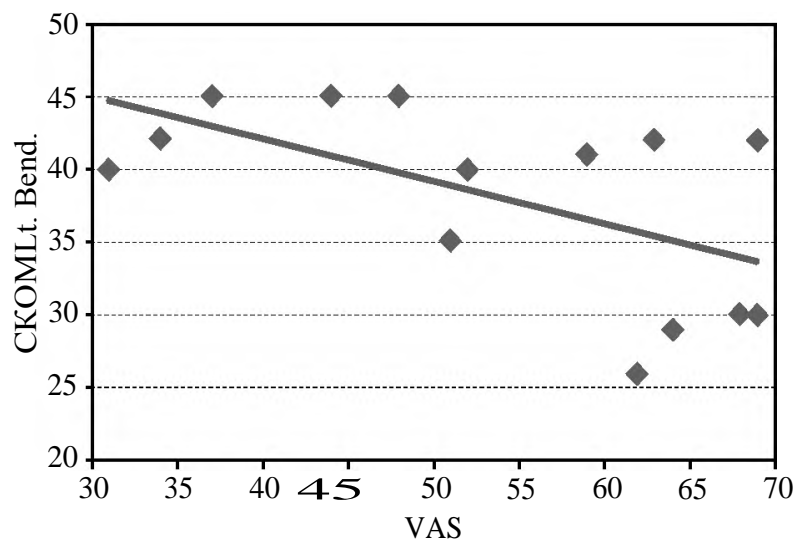

Fig. (4): Correlation between VAS and CROM Lt. Bend.

the presence of neck pain. Among the cervical muscles, the Sternocleidomastoid (SCM) muscle might play a significant role in whiplash injury. Muscle is the first injured structure, followed by injury to the ligaments and finally the facet joints. SCM contraction would serve to restrain side bending movement of the head. It was suggested that the SCM is activated by bodily movement and occurs early enough to serve as a protective function for the cervical spine during angular acceleration of the head. This is agreed with Brault et al., O'Leary et al., Ivonne et al., Siegmund et al. and Kumar et al., [6,24-27].

The reason for lateral flexion motion being more limited than rotational motion may be due to rotational movements (horizontal plane) are likely more frequently used than side bending movement during daily activities in rapid response to surrounding stimuli [28]. This reason come with agreement with Kasch et al., [29] who found that 
neck pain and neck lateral flexion are related inversely during the first 6 months after whiplash injury.

Whilst only cervical bending movement to right and left were limited due to pain after grade II whiplash injury in this study, previous researchers have noted limitation in whiplash injury subjects in other movement directions including extension, flexion, right rotation and left rotation [30-32]. The reasons for this discrepancy are unclear. The majority of subjects in this study reported bilateral neck pain discounting the possibility that the side of pain is responsible for this finding. Hand dominance was not considered in this study and could be associated with this finding. Additionally, the subjects in this study were only with chronic grade II whiplash injury as opposed to the abovementioned studies using acute subjects as the study of Sterling et al., [30] or chronic cases with all grades of whiplash injury as the study of Treleaven et al., [31] and the other of Heikkila and Astrom [32].

\section{Conclusion:}

From the obtained results of this study, it can be concluded that pain limit the cervical bending movement to right and left after grade II whiplash injury without any effect on the other movements.

\section{References}

1- MAUJEAN A., STERLING J. and STERLING M.: What information do patients need following a whiplash injury? The perspectives of patients and physiotherapists. Disability and Rehabilitation, 40 (10): 1135-41, 2018.

2- MATTEO C., ANTONELLA C., ALESSANDRO C., et al.: Association Between Clinical and Neurophysiological Outcomes in Patients With Mechanical Neck Pain and Whiplash-associated Disorders. The Clinical Journal of Pain, 34 (2): 95-103, 2018.

3- STERLING M., et al.: Characterization of acute whiplashassociated disorders. Spine, 29 (2): 182-8, 2004.

4- GUNTER P.: The biomechanics of whiplash injury. B.C.M.J., 44 (5): 243-7, 2002.

5- WINKELSTEIN A., MCLENDON R.E., BARBIR A., et al.: An anatomic investigation of the cervical facet capsule quantifying muscle insertion area. J. Anat., 198: 455-61, 2001.

6- BRAULT J.R., SIEGMUND G.P. and WHEELER J.B.: Cervical muscle response during whiplash: Evidence of a lengthening muscle contraction. Clin. Biomech., 15: 426-35, 2000

7- JOHNSON G.M.: The sensory and sympathetic nerve supply within the cervical spine: Review of recent observations. Man. Ther., 9: 71-6, 2004.

8- YOGANANDAN N., KNOWLES S.A., MAIMAN D.J., et al.: Anatomic study of the morphology of human cervical facet joint. Spine, 28: 2317-23, 2003.
9- KEITH P., JEAN-MICHEL B., VALERIE P., et al.: Late whiplash syndrome: A clinical science approach to evidence-based diagnosis and management. World Institute of Pain, Pain Practice, 8 (1): 65-89, 2008.

10- STERLING M., JULL G., VIZENZINO B., et al.: Development of motor system dysfunction following whiplash injury. Pain, 103: 65-73, 2003.

11-HIDES J.A., JULL G.A. and RICHARDSON C.A.: Longterm effects of specific stabilizing exercises for firstepisode low back pain. Spine, 26: 243-8, 2001.

12- DALL'ALBA P., STERLING M., TREALEVEN J., et al.: Cervical range of motion discriminates between asymptomatic and whiplash subjects. Spine, 26 (19): 2090-4, 2001.

13- JULL G., KRISTJANSSON E. and DALL'ALBA P.: Impairment in the cervical flexors: A comparison of whiplash and insidious onset neck pain patients. Man. Ther., 9: 89-94, 2004.

14- STERLING M., JULL G. and KENARDY J.: Physical and psychological predictors of outcome following whiplash injury maintain predictive capacity at long term follow-up. Pain, 122: 102-8, 2006.

15- BOER A., LANSCHOT J., STALMEIER P., et al.: Is a single-item visual analogue scale as valid, reliable and responsive as multi-item scales in measuring quality of life? Qual. Life Res., 13: 311, 2004.

16- BURCKHARDT C.S. and JONES K.D.: Adult measures of pain: The McGill Pain Ouestionnaire (MPQ). Rheumatoid arthritis pain scale (RAPS), short-form McGill Pain Questionnaire (SFMPQ), Verbal Descriptive Scale (VDS), Visual Analog Scale (VAS) and West Haven-Yale Multidisciplinary Pain Inventory (WHYMPI). Arthritis Rheum, 49: 96-104, 2003.

17- JENSEN M.P., CHEN C. and BRUGGER A.M.: Interpretation of visual analog scale ratings and change scores: A reanalysis of two clinical trails of post-operative pain. J. Pain., 4: 407-14, 2003.

18- TOUSIGNANT M., DUCLOS E., LAFLECHE S., et al.: Validity Study for the Cervical Range of Motion Device Used for Lateral Flexion in Patients With Neck Pain. Journal of Spine, Cervical Spine, 27 (8): 812-7, 2002.

19- TOUSIGNANT M., BELLEFEUILLE L., O'DONOUGHUE S., et al.: Criterion Validity of the Cervical Range of Motion (CROM) Goniometer for Cervical Flexion and Extension. Journal of Spine, Cervical Spine, 25 (3): 32430, 2000.

20- LEE H., NICHOLSON L.L., ADAMS R.D., et al.: Proprioception and rotation range sensitization associated with sub-clinical neck pain. Spine, 30: 60-7, 2005.

21- HYUNG I.H., KIM S.S. and LEE S.Y.: The effect of immediate pain and cervical ROM of cervical pain patients on stretching and manipulation. J. Korean Soc. Phys. Ther., 21: 1-7, 2009.

22- OH S.G. and YU S.H.: Biomechanical changes in lower quadrant after manipulation of low back pain patients with sacroiliac joint dysfunction. J. Korean Soc. Phys. Ther., 8: 167-80, 2001

23- JULL G.A., FALLA D., VICENZINO B., et al.: The effect of therapeutic exercise on activation of the deep cervical 
flexor muscles in people with chronic neck pain. Man. Ther., 14: 696-701, 2009.

24- O'LEARY S., FALLA D. and JULL G.: The relationship between superficial muscle activity during the craniocervical flexion test and clinical features in patients with chronic neck pain. Manual Therapy, 16 (5): 452-5, 2011.

25- IVONNE A., KEN R., GISEON H.E.O., et al.: The role of sternocleidomastoid muscle in simulated low velocity rear-end impacts. Eur. Spine J., 15 (6): 876-85, 2006.

26- SIEGMUND G.P., SANDERSON D.J., MYERS B.S., et al.: Awareness affects the response of human subjects exposed to a single whiplash-like perturbation. Spine, 28: 671-9, 2003.

27- KUMAR S., NARAYAN Y. and AMELL T.: An electromyographic study of low-velocity rear-end impacts. Spine, 27: 1044-55, 2002.

28- HILLA S., PATRICE L. and YOCHEVED L.: The Effect of Neck Pain on Cervical Kinematics, as Assessed in a Virtual Environment. Journal of Physical Medicine and Rehabilitation, 91 (12): 1884-90, 2010.

29- KASCH H., STENGAARD-PEDERSEN K., ARENDTNIELSEN L., et al.: Headache, neck pain and neck mobility after acute whiplash injury. Spine, 26: 1246-51, 2001.

30- STERLING M., JULL G., VICENZINO B., et al.: Development of motor system dysfunction following whiplash injury. Pain, 103: 65-73, 2003.

31- TRELEAVEN J., JULL G. and STERLING M.: Dizziness and unsteadiness following whiplash injury: Characteristic features and relationship with cervical joint position error. J. Rehabil. Med., 35: 1-8, 36-43, 2003.

32- HEIKKILA H. and ASTROM P.: Cervicocephalic kinaesthetic sensibility in patients with whiplash injury. Scand. J. Rehabil., 28: 133-8, 1996.

\section{العلاقة بين آلم الرقبة وثقص مدى حركية الرقبة

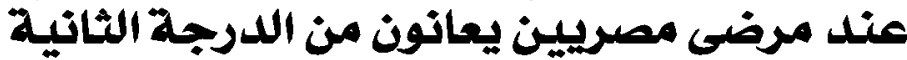 \\ من الإصابة المصعية بعادون من الرقبة}

الغرض من هذه الدراسة التحقق من وجود آى علاقة بين آلم الرقبة ونقص مدى حركة الرقبة عند مرضى مصريين يعانوف من الدرجة الثانية من الإصابة المصعية بالرقبة.

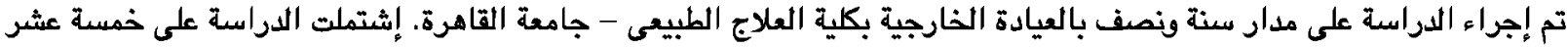

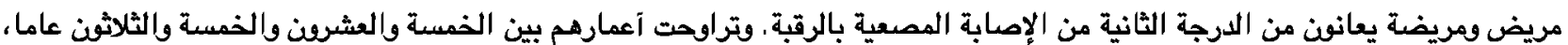

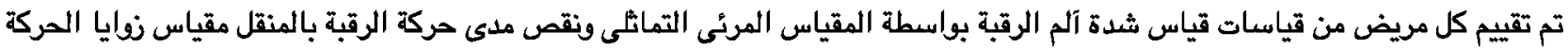
الخاص بالرقبة.

آثبتت نتائج الدراسة وجود علاقة عكسية قوية بين آلم الرقبة ومدى حركة ثنى الرقبة ناحيتى اليمين واليسار. 